\title{
Unidad temporal de hemodiálisis
}

\section{Gloria Álvarez Valdés Marta Fernández Boltá Diana Fernández Zapico Mª Luisa Martínez de Diego Flor San Martín Baragaño Cristina San Martín Escandón Julia Corujedo Piniella Mercedes López Cobiella Ana Rosa Valero Escudero}

\section{Unidad de Hemodiálisis Hospital del Oriente de Asturias}

\section{Señora Directora:}

La Unidad de Hemodiálisis del Hospital del Oriente de Asturias ha vivido una reforma física este último año, anteriormente disponía de 6 puestos para atender a un total de 24 pacientes en turnos de mañana y tarde. Hoy en día contamos con 8 puestos para atender a 32 pacientes, más 1 puesto para urgencias.

La necesidad de realizar obras para reforzar la estructura de una parte del hospital y aumentar la capacidad de nuestro servicio, obligó a cerrar temporalmente la unidad de hemodiálisis.

El traslado de los pacientes a unidades de diálisis de otros hospitales originaba una serie de problemas: debido a la orografía de la zona los desplazamientos desde el domicilio hasta el centro sanitario serían muy largos, llegando en algunos casos a las 2 horas de duración, y los cambios que produciría esta situación (dializarse en un centro nuevo, personal desconocido...) generarían ansiedad en los pacientes y sobrecarga de trabajo en las unidades de hemodiálisis receptoras.

Con el fin de evitar estos problemas se planteó la posibilidad de ubicar la unidad en otra área del hospital, intentando aportar el máximo confort al paciente y proporcionar una diálisis adecuada, manteniendo los estándares de calidad en el agua.

El principal problema surgió con el tratamiento del agua de red, que se solucionó gracias a la cesión por parte de Fresenius Medical Care ${ }^{\circledast}$ de tres máquinas portátiles (miniplantas AquaWTU) de tratamiento de purificación de agua (utilizadas en hemodiálisis domiciliaria). Cada miniplanta suministraba agua a tres monitores de hemodiálisis (quedando una de reserva).

\begin{tabular}{|c|}
\hline Correspondencia: \\
Gloria Álvarez Valdés \\
Unidad de Hemodiálisis \\
Hospital del Oriente de Asturias \\
Urbanización Castañera s/n \\
33540 Arriondas
\end{tabular}

Después se buscó el espacio físico para albergar la unidad temporal y se hicieron las obras pertinentes en una habitación de hospitalización de 4 pacientes para albergar 6 puestos de hemodiálisis.

El personal de mantenimiento instaló las tuberías, tomas de agua para los monitores de hemodiálisis, desagües que drenan el líquido de desecho de la diálisis hasta el plato de ducha del baño situado en la misma habitación, nuevo panel eléctrico y las tomas correspondientes.

El control de enfermería se instaló en el pasillo contiguo a la habitación, separado de la unidad de hospitalización por un tabique de Pladur ${ }^{\circledast}$. El baño se utilizó como control séptico; acondicionamos los armarios roperos para albergar medicación y material fungible, y compartimos el almacén con la planta de hospitalización.

Se realizaron controles del agua tratada: mensualmente análisis microbiológicos, al inicio y a los 3 meses análisis bioquímicos y diariamente análisis de cloraminas y $\mathrm{pH}$. Las miniplantas portátiles precisaban un sencillo mantenimiento, que no supuso un aumento en la carga de trabajo, pero sí vigilancia de las mismas en cada turno. Se consiguieron flujos adecuados de agua tratada que permitieron dializar sin problemas.

Con esta organización se consiguió una hemodiálisis correcta, con buena calidad del agua. Los cultivos del agua tratada fueron siempre negativos. Los resultados de los análisis bioquímicos fueron correctos. Los análisis diarios de los niveles de $\mathrm{pH}$ y cloraminas estuvieron en todo momento dentro de los límites adecuados ( $\mathrm{pH}$ medio: 6,8 y nivel medio de cloraminas: $0,0 \mathrm{mg} / \mathrm{l}$ ).

A esto tenemos que sumar el alto grado de satisfacción por parte de los pacientes que nos transmitieron en numerosas ocasiones.

Como conclusión, creemos que la creación de una unidad temporal de hemodiálisis no supone un alto coste, la instalación y el manejo son sencillos y los resultados óptimos, siendo preferible al cierre y traslado de pacientes a otras unidades. 